\title{
Analysing the life index of diamond cutting tools for marble building stones based on laboratory and field investigations
}

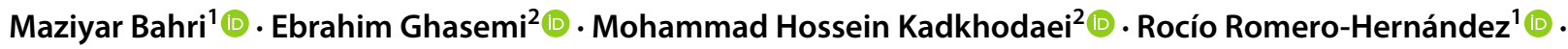 \\ Emilio J. Mascort-Albea ${ }^{1}$ (1)
}

Received: 22 January 2021 / Accepted: 15 July 2021 / Published online: 28 July 2021

(c) The Author(s) 2021

\begin{abstract}
Cutting tool wear constitutes one of the principal parameters in the processing cost of building stone. The life index of the cutting tool is obtained by evaluating the wear of diamond segments in the processing plants and examining the main parameters thereof. The purpose of this study is to determine the life index of the diamond cutting tool by considering the physico-mechanical properties of marble stones and the operational parameter of cutting speed. To this end, a dataset was provided by collecting the data from eight building stone processing plants in the provinces of Tehran, Isfahan, and Yazd of Iran. In this regard, the number of square metres of building stone that every diamond cutting tool can cut during its lifetime is defined as the cutting tool life index (TLI). After collecting the required data, SPSS software was employed for statistical analysis. The results revealed that the Brazilian tensile strength is the main parameter that affects the cutting tool life index. Linear and non-linear regression analyses were then considered for the development of predictive models for the TLI based on the Brazilian tensile strength. The performance of the developed models was subsequently examined by using three different criteria: the coefficient of determination, the variance accounted for, and the root-mean-square error. The results of this study show that the non-linear predictive model of the TLI presents a very good performance, and thus, the diamond cutting tool life index can be obtained for marble stones by considering the model developed herein.
\end{abstract}

Keywords Diamond cutting tool · Tool life index (TLI) - Marble building stones · Physico-mechanical properties ·

Statistical analysis

\section{Introduction and literature review}

Generally, the processing operation for building stone is carried out in a stone processing plant in two stages: cutting and polishing. During the cutting stage, the blocks extracted from the mines are cut into slabs to the dimensions desired. This process is accomplished with cutting machines (gangsaws and saws) equipped with the diamond

Maziyar Bahri

mazbah@alum.us.es

1 Escuela Técnica Superior de Arquitectura, Departamento de Estructuras de La Edificación E Ingeniería del Terreno, Instituto Universitario de Arquitectura Y Ciencias de La Construcción, Universidad de Sevilla, Avenida de Reina Mercedes 2, 41012 Sevilla, Spain

2 Department of Mining Engineering, Isfahan University of Technology, 8415683111 Isfahan, Iran cutting segments. During the second stage of the processing operation, the slabs are prepared in the polishing process.

In the processing plant, the majority of the machine failures and the highest costs are incurred in the first stage since the machines are directly involved with the stone block; the energy consumption in cutting marble is approximately three times that consumed in the polishing stage (Traverso et al. 2010). The reduction of this cost therefore plays a vital role in enhancing profitability. A gangsaw and its cutting disc (equipped with a diamond segments) are depicted in Figs. 1a, b, respectively.

The evaluation of the wear rate of the cutting segments can be considered as one of the most effective aids towards reducing the cutting cost. The wear of diamond cutting segments constitutes a crucial technical and economical parameter that can be utilised to estimate the consumption rate of the cutting tools and to optimise the cutting operation process. Furthermore, this parameter can prevent possible undesirable incidents, such as breaking the cutting discs and 
Fig. 1 (a) A gangsaw in the process of cutting a stone. (b) Putting the diamond segments onto the cutting disc

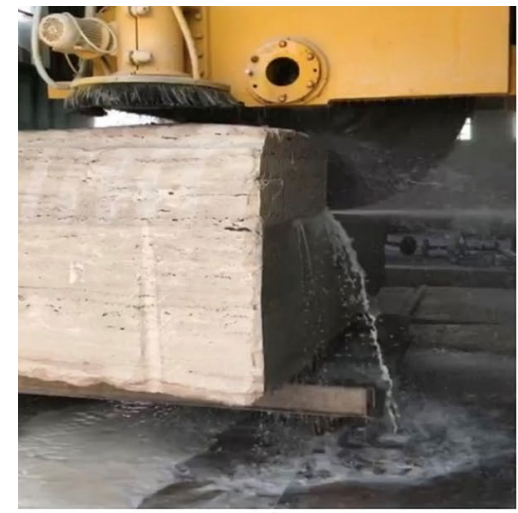

(a)

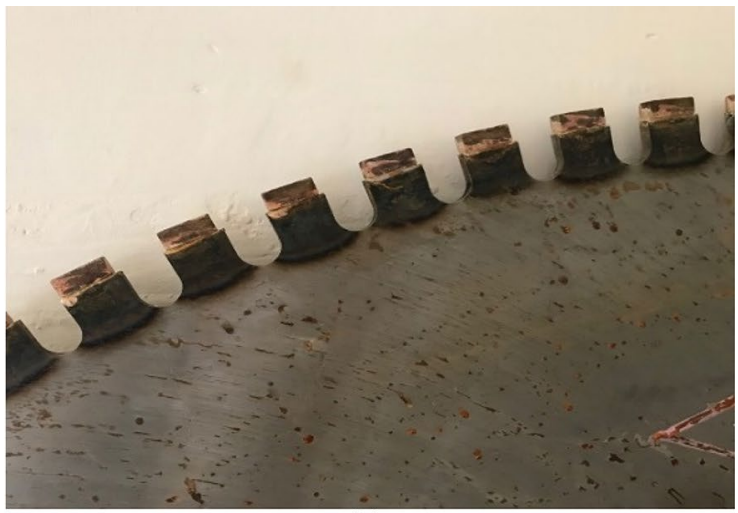

(b) crushing stone during the cutting operation. This prevention can lead to the increment of cutting speed and results in the enhancement of the manufacturing throughput. The amount of cutting tool wear depends both on the physico-mechanical properties of the stone and on the operational parameters of the cutting machine. This factor plays a significant role in the performance of the cut stone.

In general, the wear of diamond segments is affected by several parameters. The most important parameters include the following (Ozcelik and Yilmazkaya 2010):

1. The properties of the diamond and its constituent matrix: the type of diamond, the concentration of diamonds, particle size, and hardness of the metal disc.

2. The physico-mechanical and mineralogical properties of the stone to be cut.

3. The segment production method.

4. The cutting operational parameters (i.e., rotation speed, penetration rate, and cutting depth).

5. The cutting technique (i.e., cut-up or cut-down).

6. Cooling agents (i.e., type and flow of coolant).

7. Cutting machine conditions.

8. Operator skills.

All of these parameters play a significant role in the wear of diamond segments. However, the physico-mechanical and mineralogical properties of stone are of much greater significance than other parameters. In this regard, many researchers have investigated the wear of diamond cutting tools by considering the parameters that affect them, especially those on a laboratory scale. Decades ago, Mamalis et al. (1979) investigated various modes of the wear of diamond segments for two types of granite rock. It was observed that the geometry and wear characteristics of diamond grains differ in these two types of rocks. Furthermore, the research stated that this difference arises from the diversity in their texture.

Ertingshausen (1985) performed the cut-down and cut-up experiments for processing a type of red granite. The author found that in a shallow cut, the wear of cut-down processing is greater than the cut-up processing. Complementarily, Wright et al. (1986) conducted cutting experiments on six different types of granite rocks. The results demonstrated that the salinity hardness parameter is a desirable indicator for cutting blade wear. Cassapi (1987) predicted the wear rate based on rock properties. The findings of that investigation revealed that the grain size and rock hardness are the best parameters for the evaluation of the wear of diamond segments.

Jennings and Wright (1989) estimated the wear of a cutting blade segment for granite considering its mechanical characteristics and mineralogical properties. The results of their study indicated that the amount of wear not only depends on the quartz content but also relates to the mechanical characteristics of the rock, including the uniaxial compressive and tensile strengths of the rock. Continuing this approach, Liao and Luo (1992) performed cutting experiments on Indian-Imperial granite with different segment materials. According to the results of their study, the wear of diamond grains makes a hole within the matrix forming the segment. They found that diamond segments with greater hardness have lower wear and higher efficiency.

Wang et al. (1995) compared the cooling techniques for cutting discs and diamond segments in building stone processing plants. The findings of that study revealed that the type of cooling agent plays a critical role in the life of diamond segments. The following year, Luo (1996) investigated the wear behaviour of diamond grains based on the constituent matrix in granite samples, and Unver (1996) utilised statistical models for the estimation of the specific wear rate (SWR) by considering the physico-mechanical properties of the rock.

During the first decade of the twenty-first century, progress was made in predictive monitoring of the main wear parameters. Eyuboglu et al. (2003) predicted the wear of cutting segments for andesite rock considering uniaxial compressive strength, tensile strength, elastic modulus, and salinity hardness. Ersoy and Atıcı (2004) estimated the wear of the cutting tool while considering various items, including 
the following: specific shear energy, energy dissipation, grain size, quartz content, silica content, shear strength, Brazilian tensile strength, bending strength, Young's modulus, Mohs hardness, salinity hardness, Schmidt hammer hardness, the Cerchar abrasivity index, the Shimazaki factor, impact resistance, porosity, density, and the Böhme abrasion test on 10 granite samples. Among the above experiments, it is worth mentioning that the Böhme abrasion test is one of the most widely used methods for the determination of the abrasion resistance of stones through abrasion (Strzałkowski et al. 2020). For this purpose, rotating discs are used in combination with abrasive grains (Yavuz et al. 2008). Additionally, further parameters, such as Vickers hardness, were considered in the estimation of the wear of the cutting tool for rocks, such as granite, in the research of Sánchez Delgado et al. (2005). In this respect, the Vickers hardness test enables a factor to be determined that relates the force applied through the Vickers hardness tester and the existing contact surface of the material analysed (Guo et al. 2018; Shahdad et al. 2007).

Kahraman et al. (2006) developed a regression model to predict the number of carbonate minerals produced by diamond segments. They estimated the cutting of carbonate rocks by evaluating the effect of various parameters on the statistical models. These parameters are comprised of Schmidt hammer parameters, point load resistance, impact strength, and $p$-wave velocity. Moreover, a theoretical model was developed to express the relationship between specific shear energy and rock properties.
The following year, Buyuksagis (2007) investigated the relationship between specific wear rate and specific cutting energy based on the physico-mechanical properties derived from six types of granite and whether the rock cutting direction was cut-up or cut-down. Moreover, Fener et al. (2007) estimated the capability of gangsaws in building stone processing plants. To this end, they collected a dataset from three building stone processing plants in Turkey. The dataset was comprised of uniaxial compressive strength, Brazilian tensile strength, Schmidt hammer hardness, point load resistance, the impact resistance index, and Los Angeles hardness, and wave velocity. This data was provided by eight samples of carbonate rock.

The advances achieved in the last decade have made it possible to obtain a state of the art understanding of the factors influencing these technological processes. In this respect, Güney (2011) predicted the cuttability of rock based on the following parameters: crystal size, salinity hardness, and Schmidt hammer hardness. This research was applied to five marble samples extracted from seven building stone processing plants in Turkey. Complementarily, Gunes Yilmaz et al. (2011) conducted studies on nine types of granite rock while considering physicomechanical and lithological properties. They subsequently evaluated the wear performance of the diamond cutting tool in gangsaws and introduced equations to estimate the specific wear rate based on physico-mechanical and lithological properties: one such equation is mentioned in Table 1.

Table 1 Summary of equations proposed for studies of diamond segment wear

\begin{tabular}{lll}
\hline Reference & Studied on & Equation \\
\hline $\begin{array}{l}\text { Gunes Yilmaz et al. (2011) } \\
\text { Sadegheslam et al. (2013) }\end{array}$ & Specific wear rate & $S W R=97.598+2.403 q_{\text {max }}$ \\
Pumac (2015) & Production rate & $P=\frac{10^{2.772}}{Q_{c}^{0.272} E^{0.712} U C S^{1.023}}$ \\
Sun et al. (2016) & Areal slab production rates & $A S P R=-1.622 C A I+0.347 K+10.692$ \\
Goktan and Gunes Y1lmaz (2017) & Wear rate & $W_{r}=29.77-1.357 Q_{c}+2.116 B S+0.244 U C S$ \\
Akhyani et al. (2018) & Specific wear rate & $S W R=-333.84+0.0718 K H+1.436 d+251.124 V_{f}$ \\
Zhang et al. (2019) & Wear rate & $W_{r}=\frac{I^{15.01} \times T^{0.619}}{10^{24.92}}$ \\
& Unit wear & $U W=208.25-48.75 V_{f}+12.31 n_{k}-17.37 V_{f} n_{k}$ \\
& & $+31.78 V_{f}^{2}+6.47 n_{k}^{2}-29.19 V_{f}^{2} n_{k}$ \\
Inal et al. (2019) & & $+12.66 V_{f} n_{k}^{2}+V_{f}^{3}+4.78 n_{k}^{3}$ \\
Buyuksagis et al. (2020) & Specific wear rate & $S W R=-1226+19.13 P S+434.1 T S$ \\
Rajpurohit et al. (2020) & Specific wear rate & $W S=572 K H^{0.101}+51.37 C A I+2.895 B T S^{1.44}-811.35$ \\
Bayram and Kulaksiz (2021) & Unit wear of diamond segment & $W S=32.834+1.2722 C A I$ \\
& Unit wear of diamond segment & $U W=-5.57+0.1918 A R+0.1718 H_{S h o r e}+0.407 T S$ \\
& & $-0.1616 E M-0.872 I S+0.0385 B W$ \\
\hline
\end{tabular}

WS unit wear of diamond segment, $C A I$ Cerchar abrasivity index, $K H$ Knoop Hardness, BTS Brazilian tensile strength, $U W$ unit wear, $V f$ feed rate, $n_{k}$ crank speed, $S W R$ specific wear rate, $d$ cutting depth, $I$ ampere consumption, $W_{r}$ wear rate, $T$ toughness, $P S$ peripheral speed, $T S$ traverse speed, $E$ Young's modulus, $Q_{c}$ quartz content, $P$ production rate, $A S P R$ areal slab production rates, $K$ deformation coefficient, $B S$ bending strength, $q_{\max }$ quartz maximum grain size, $H_{\text {Shore }}$ shore hardness, $A R$ advance rate, $T S$ tensile strength, EM modulus of elasticity, $I S$ impact strength, $B W$ block weight 
With a similar methodology, Aydin et al. (2013) estimated the wear of the saw blade using the operational parameters of the cutting machine and the physico-mechanical parameters of stone. This work was performed by examining nine types of granite stone. Sun et al. (2016) estimated saw blade wear by considering both the physico-mechanical properties of stone (i.e., salinity hardness, density, compressive strength, and Brazilian tensile strength) and the mineralogical properties of granite. Nevertheless, Sadegheslam et al. (2013) emphasised that the coefficients of the efficiency equations and the cutting performance should be reasonable, and argued that an increase in the stone strength parameters, hardness, and wear can lead to the reduction of the stone cuttability. They developed industrial surveys for 17 different types of stone ( 7 types of carbonate stone and 10 types of granite stone). Thanks to this investigation, statistical equations were developed to predict the efficiency and performance of gangsaws by considering the geo-mechanical properties of stone (Table 1).

Goktan and Gunes Yilmaz (2017) predicted the wear rate of the cutting tool using computational processes based on the NP-hardness (non deterministic polynomial-time hardness) of 9 granite samples and the two parameters of the cutting speed and cutting depth. With a similar methodological approach, Turchetta and Sorrentino (2019) predicted the wear of the diamond segment and shear force in granite rock. Additionally, Zhang et al. (2019) predicted the wear of diamond segments per unit area based on processing parameters (feed rate and crank speed). They investigated the mechanism of diamond segment wear based on microscopic studies and then performed various tests under different processing parameters (feed rate and crank speed) and developed a reliable model to evaluate the diamond segment wear using Design Expert software. Finally, to increase the productivity and reduce the wear of the segments, the aforementioned authors optimised the parameters.

Within the last year, Buyuksagis et al. (2020) have developed linear and non linear models to predict the specific energy consumed in cutting and the specific tool wear rate based on the effect of physical and mechanical properties of carbonate rocks, such as Brazilian tensile strength, porosity, bending strength, the Knoop hardness test, and the Cerchar abrasivity index, as well as the properties of diamond segment matrices, such as diamond concentration, tin percentage, copper percentage, Vickers hardness, and the mean diamond grain size on the performance and tool life of diamond cutting tools. Likewise, Rajpurohit et al. (2020) have evaluated the parameter of the Cerchar abrasivity for a type of granite rock in India, thereby predicting the wear of diamond wire cutting in the Rajasthan stone quarries of India. They also predicted the wear of the diamond segments in the building stone processing plant. Wang et al. (2020) have investigated two types of diamond cutting segments with different structures in their constituent matrix. They performed the experiments for two cutting modes (horizontal cutting and alternating oscillating cutting). Finally, Bulut et al. (2021) have performed an on site field test on an industrial scale in Turkey, on the gangsaw blade segments. The amount of silver $(\mathrm{Ag})$ and aluminum $(\mathrm{Al})$ at the matrix of the segment was studied along with that of other materials in order to gain sufficient wear properties of diamond segments. In that research, the andesite stone was cut with different diamond segments, produced by mixing various ratios of metal powders.

A summary of the recent research on the wear of diamond segments that developed equations is shown in Table 1. In addition, recent research on the gangsaw has been described in Table 2. As mentioned earlier, it is necessary to evaluate the stone cutting tool (in general, the evaluation of the use of the stone cutting tool and diamond segments) during the processing stage of the building stone. This mitigates not only the probability of the occurrence of incidents but also optimises the speed of the stone cutting operation, which is directly related to plant production. Furthermore, the results of the literature review revealed that the stone properties and the operational parameters of the cutting machine constitute the most vital parameters that affect the wear and the consumption of the cutting tools.

The purpose of this study is to develop a model for the evaluation of the life index for the diamond cutting tool

Table 2 Recent studies on gangsaws

\begin{tabular}{|c|c|c|}
\hline Reference & Studied on & Parameter used \\
\hline Mikaeil et al. (2018) & Sawability & $\begin{array}{l}\text { Uniaxial compressive strength, Indirect Brazilian tensile strength, hardness, } \\
\text { abrasivity }\end{array}$ \\
\hline Dormishi et al. (2018) & Energy consumption & $\begin{array}{l}\text { Uniaxial compressive strength, Indirect Brazilian tensile strength, hardness, } \\
\text { abrasivity }\end{array}$ \\
\hline Shaffiee Haghshenas et al. (2019) & Maximum electrical current & $\begin{array}{l}\text { Mohs hardness, uniaxial compressive strength, Schimazek's fabrasiveness } \\
\text { factor, Young's modulus, production rate }\end{array}$ \\
\hline Dormishi et al. (2019) & Maximum energy consumption & $\begin{array}{l}\text { Uniaxial compressive strength, indirect Brazilian tensile strength, hardness, } \\
\text { abrasivity, Young's modulus, quartz content }\end{array}$ \\
\hline Bulut et al. (2021) & Wear characteristics & Addition of silver and aluminium to the matrix of the segment \\
\hline
\end{tabular}


using the physico-mechanical properties of the stone and the operation parameters of the cutting speed, and it should be borne in mind that this research has been carried out on small processing plants. To this end, a dataset was provided by collecting eight marble samples from building stone processing plants in the Iranian provinces of Tehran, Isfahan, and Yazd. Subsequently, the influences on the cutting tool life of the physico-mechanical properties of the stone (e.g., density, porosity, Schmidt hammer hardness, uniaxial compressive strength, Brazilian tensile strength, and $P$-wave velocity) and the cutting speed of the cutting tool were investigated. Furthermore, the single and multivariate statistical models have been utilised to develop and evaluate the predictive cutting tool life index. Furthermore, it should be borne in mind that statistical models have been developed for processing plants that all employed the same gangsaw and cutting tools. Although recent studies on gangsaws (Table 2) have been carried out to estimate the rate of wear on the diamond segments, energy consumption, and sawability, this study is focused on the on-site segment life, under real working conditions in the small processing plants. In addition, this study strives to use physico-mechanical properties of the stone, which is affordable for small scale businesses.

\section{Description of the database}

As stated above, this study aims to investigate the effect of the physical and mechanical properties of the stone on the wear of diamond segments in building stone processing plants. For the development of predictive models for the cutting tool life, the cutting process has been examined across various types of marble stone in eight building stone processing plants in Iran (Table 3).

\section{Cutting parameters}

According to the studies of Aydin et al. (2013), machine parameters play a critical role in the wear and life of the

Table 3 The processing plants studied

\begin{tabular}{llll}
\hline Row & Plant name & Area & Symbol \\
\hline 1 & Dana & Yazd & DA \\
2 & Besat & Rezvanshahr Isfahan & BE \\
3 & Sadaf & Yazd & AB \\
4 & Afshary & Yazd & AF \\
5 & Kohi & Dolat Abad Isfahan & BA \\
6 & Sange Iranian & Mahmood Abad Isfahan & HA \\
7 & Salsali & Shams Abad Tehran & SA \\
8 & Delta & Mahmood Abad Isfahan & MI \\
\hline
\end{tabular}

cutting tool. Therefore, these stone processing plants should be studied under equal conditions in order to eliminate errors caused by variation between the types of diamond segments and gangsaw machines.

To this end, all of these plants were equipped with a single disc gangsaw and the same diamond segment. The diameter of the cutting discs was $160 \mathrm{~cm}$. Also, the rotational speed of the cutting discs and motor power in all eight building stone processing plants were approximately 650-700 (rpm) and 110-130 (Kw), respectively. All eight plants employed the same brand of gangsaw, and therefore, these parameters had a similar range. It is worth mentioning that these parameters were changed randomly in building stone processing plants, and consequently, their parameters could not be used in this research. Moreover, diamond segments on the cutting discs used in building stone processing plants were of the same material and model. Therefore, the cutting machine and cutting segments of all stone processing plants are similar to each other. They also had the same cutting conditions. As mentioned earlier, for this research, the stone processing plants selected should use the same machine and diamond segments.

The only variable in this study was the feeding rate of cutting discs. Hence, in this research, this variable is presented as the speed of cutting discs (SPC) in metres per minute (Fig. 2). This parameter is measured in the field study by using a stopwatch. In this way, traverse speed in the roundtrip motion of the cutting discs from point $A$ to point $\mathrm{B}$ and from point $\mathrm{B}$ to point $\mathrm{A}$ was measured five times for each factory, and its average is given in Table 4.

It should be noted that the unit of measurement of the SPC is metres per minute, and by examining the cutting speed of cutting discs and the strength properties of stone, it can be observed that the harder the stone and the faster the cutting speed, then the greater the wear of the diamond segments, and the shorter their life.

The single-disc gangsaw is chosen due to its diamond segments having a shorter life than that of the segments of the multi disc gangsaws. Therefore, the data collection process is implemented in less time. The reason for their shorter

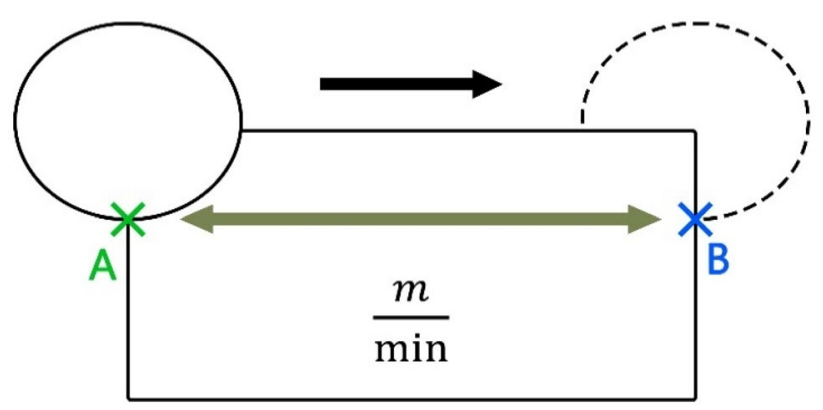

Fig. 2 Measuring the speed of the cutting disc 
Table 4 The average speed of the cutting discs

\begin{tabular}{lllllllll}
\hline Sample & DA & BE & AB & AF & BA & HA & SA & MI \\
\hline SPC $(\mathrm{m} / \mathrm{min})$ & 26.25 & 28.40 & 26.00 & 23.00 & 20.00 & 21.00 & 22.00 & 27.00 \\
\hline
\end{tabular}

life is that the cutting forces in the multi disc gangsaws are divided across several discs. Moreover, the movement speed of the disc in the multi disc block sawing machine is slower than that in a single disc gangsaw, and therefore, it undergoes less wear as compared to a single-disc gangsaw (Yurdakul 2015). According to the field study, the diamond cutting tool in a multi disc gangsaw can be utilised for an average of 180 days. However, a single-disc gangsaw usually lasts only between 20 and 30 days.

\section{Physico-mechanical tests in the laboratory}

The physical properties (e.g., density, porosity, and $P$-wave velocity) and mechanical characteristics (e.g., uniaxial compressive strength, Brazilian tensile strength, and Schmidt hammer hardness) were specified for the marble samples of those stone processing plants. The results of these values are given in Table 5. Following the criteria established by Feng (2017), it should be noted that the uniaxial compressive strength, Brazilian tensile strength, and $P$-wave velocity are measured based on the ASTM C170, ASTM C496-71, and ISRM standards, respectively. Schmidt hammer type $\mathrm{L}$ and the ISRM standard were used in this test. At least 20 tests were conducted on each sample at 20 points whose minimum distances were equal to the diameter of the plunger. The numbers were sorted into descending order, the lowest $50 \%$ were omitted, and the average of the remaining was calculated and multiplied by the calibration coefficient: this number is known as the Schmidt hardness number.

\section{Tool life index (TLI)}

A field survey was performed to collect the data regarding the area of stone that a plant can produce during the life of a diamond cutting tool. Thus, the parameter of the tool life index (TLI) was recorded as the output parameter. This index indicates when the diamond segments should be changed in a building stone processing plant (based on cutting area). In other words, the number of square metres that every diamond segment can cut during its lifespan (this index is expressed in terms of $\mathrm{m}^{2} /$ tool). Table 6 provides the cutting area that every diamond cutting tool can cut during its lifespan (based on the plants studied herein). For instance, in the DA processing plant, after $4050 \mathrm{~m}^{2}$ of stone cutting, the segments should be replaced.

\section{Statistical evaluation}

In this section, SPSS Statistics version 26 (George and Mallery 2016) was employed with an academic licence to investigate the relationship between the cutting tool life, physico-mechanical properties, and the operational parameter of the cutting disc speed. The regression analysis was developed to investigate the linear and non-linear relationships between the cutting tool life index, physico-mechanical properties, and the operational parameter of the cutting speed in the machine.

\section{Single regression analysis}

The purpose of this type of study is to find the relationship between the input and output parameters. To this end, it is applied to perform multivariate regression analyses (McCormick and Salcedo 2017). In this section, the best fit is selected for independent variables by considering the linear, logarithmic, exponential, and power models. In this
Table 5 The physicomechanical properties for marble samples in this study

\begin{tabular}{lllllll}
\hline Sample & $\begin{array}{l}\text { Schmidt } \\
\text { hardness }\end{array}$ & Density $\left(\mathbf{g} / \mathbf{c m}^{\mathbf{3}}\right)$ & Porosity & $\begin{array}{l}\text { Brazilian tensile } \\
\text { strength }(\mathbf{M P a})\end{array}$ & $\begin{array}{l}\text { Uniaxial compressive } \\
\text { strength }(\mathbf{M P a})\end{array}$ & $\begin{array}{l}\boldsymbol{P} \text {-wave } \\
\text { velocity } \\
(\mathbf{m} / \mathbf{s})\end{array}$ \\
\hline $\mathrm{DA}$ & 56.2 & 2.60 & 2.54 & 9.82 & 98.72 & 6119 \\
$\mathrm{BE}$ & 60.6 & 2.62 & 2.58 & 14.91 & 95.79 & 6317 \\
$\mathrm{AB}$ & 58.7 & 2.55 & 3.62 & 11.08 & 91.07 & 6104 \\
$\mathrm{AF}$ & 57.6 & 2.57 & 2.59 & 9.05 & 94.00 & 6119 \\
$\mathrm{BA}$ & 52.0 & 2.62 & 1.61 & 7.82 & 90.00 & 5905 \\
$\mathrm{HA}$ & 57.0 & 2.60 & 1.40 & 7.81 & 92.53 & 6100 \\
$\mathrm{SA}$ & 52.6 & 2.66 & 1.09 & 7.58 & 94.48 & 6094 \\
$\mathrm{MI}$ & 66.0 & 2.60 & 2.19 & 15.20 & 110.00 & 6396 \\
\hline
\end{tabular}


Table 6 The tool life index (TLI) for different types of stone

\begin{tabular}{lllllllll}
\hline Sample & DA & BE & AB & AF & BA & HA & SA & MI \\
\hline TLI $\left(\mathrm{m}^{2} /\right.$ tool $)$ & 4050 & 3900 & 4000 & 4150 & 4300 & 4200 & 4400 & 3800 \\
\hline
\end{tabular}

regard, the coefficient of determination is specified between every input parameter and the output parameter. The main parameters that affect the cutting tool life index can then be determined.

Table 7 provides the coefficient of determination for independent variables based on simple regression analysis. According to the table, the most effective parameters for the tool life index are comprised of the Schmidt hammer hardness, Brazilian tensile strength, $P$-wave velocity, and the cutting speed of the cutting discs. These parameters were therefore utilised as input variables, and these are also employed for the development of the linear and non-linear models. As an example, the linear relationships between the parameters of the Schmidt hammer hardness, Brazilian tensile strength, $P$-wave velocity, cutting disc speed, and the cutting tool life index are shown in Fig. 3. It can be observed that there is a non-linear relationship between the parameters of the Schmidt hammer hardness, Brazilian tensile strength, $P$-wave velocity, cutting disc speed, and the cutting tool life index. These parameters have an indirect relationship with cutting tool life. In other words, an increase in the Schmidt hammer hardness, Brazilian tensile strength, $P$-wave velocity, and cutting disc speed can lead to the reduction of the cutting tool life. This result correlates with the engineering logic.

\section{Multiple linear regression analysis}

Linear models are defined as the relationship between two or more input variables (independent variables) and an output variable (dependent variable). The output variable is regulated by fitting a linear equation into the data (McCormick and Salcedo 2017). In this study, the linear equation is developed based on the data available in the SPSS software environment. This equation is in the form of Eq. 1 with a coefficient of determination of 0.984 .

$$
\begin{aligned}
T L I & =(-39.047 \times S c h)-(15.813 \times B T S) \\
& +(0.727 \times V p)-(29.689 \times S P C)+2762.973
\end{aligned}
$$

where TLI is the cutting tool index $\left(\mathrm{m}^{2} /\right.$ tool $), \mathrm{Sch}$ is the Schmidt hammer hardness, BTS is the Brazilian tensile strength (MPa), $V_{p}$ is the $P$-wave velocity $(\mathrm{m} / \mathrm{s})$, and $\mathrm{SPC}$ is the speed of the cutting disc $(\mathrm{m} / \mathrm{min})$. As mentioned earlier, the cutting tool index has an indirect relationship with the Schmidt hammer hardness, Brazilian tensile strength, $P$-wave velocity, and the speed of the cutting disc. However, Eq. 1 expresses a direct relationship between the $P$-wave velocity parameter and the cutting tool life index. This is contrary to engineering logic, which is mentioned in the previous section and Fig. 3c. The reason for this assumption of a direct relationship is the very high correlation (from the point of view of rock mechanics) between the input parameters (Fig. 4). Additionally, Table 8 shows the correlations between the parameters used based on Pearson correlation criteria.

This problem is referred to as the multi-collinearity problem (Farrar and Glauber 1964; Montgomery et al. 2012; Shrestha 2020). To solve this issue, the stepwise method can be used in SPSS software to develop a regression model. The stepwise method is a statistical technique that enables the selection of variables that are better adjusted to the reality of the model analysed, through the quantification of the values of the partial Wilks factor. In this way, it constitutes an alternative to another very common method known as the forward selection technique (Al-Subaihi 2002) and is used in advanced studies to determine common patterns in material characterisation research (Sadegheslam et al. 2013; P. Zhang et al. 2020). At an operative level, the stepwise command takes into account the correlation between the parameters, selects the most effective input parameters to develop the model, and removes the other (ineffective) parameters.

Table 7 Determination coefficient values for independent variables based on single regression analysis

\begin{tabular}{llllllll}
\hline Type of trendline & $\begin{array}{l}\text { Schmidt } \\
\text { hardness } \\
\text { (Sch) }\end{array}$ & Density & Porosity & $\begin{array}{l}\text { Brazilian tensile } \\
\text { strength (BTS) }\end{array}$ & $\begin{array}{l}\text { Uniaxial compressive } \\
\text { strength (UCS) }\end{array}$ & $\begin{array}{l}\boldsymbol{P} \text {-wave } \\
\text { velocity }\left(\boldsymbol{V}_{\boldsymbol{P}}\right)\end{array}$ & $\begin{array}{l}\text { Speed of the } \\
\text { cutting machine } \\
\text { (SPC) }\end{array}$ \\
\hline Linear & 0.858 & 0.209 & 0.417 & 0.863 & 0.434 & 0.668 & 0.772 \\
Logarithmic & 0.866 & 0.207 & 0.512 & 0.900 & 0.432 & 0.665 & 0.763 \\
Exponential & 0.865 & 0.196 & 0.403 & 0.875 & 0.447 & 0.682 & 0.773 \\
Power & 0.872 & 0.193 & 0.496 & 0.908 & 0.449 & 0.678 & 0.764 \\
\hline
\end{tabular}




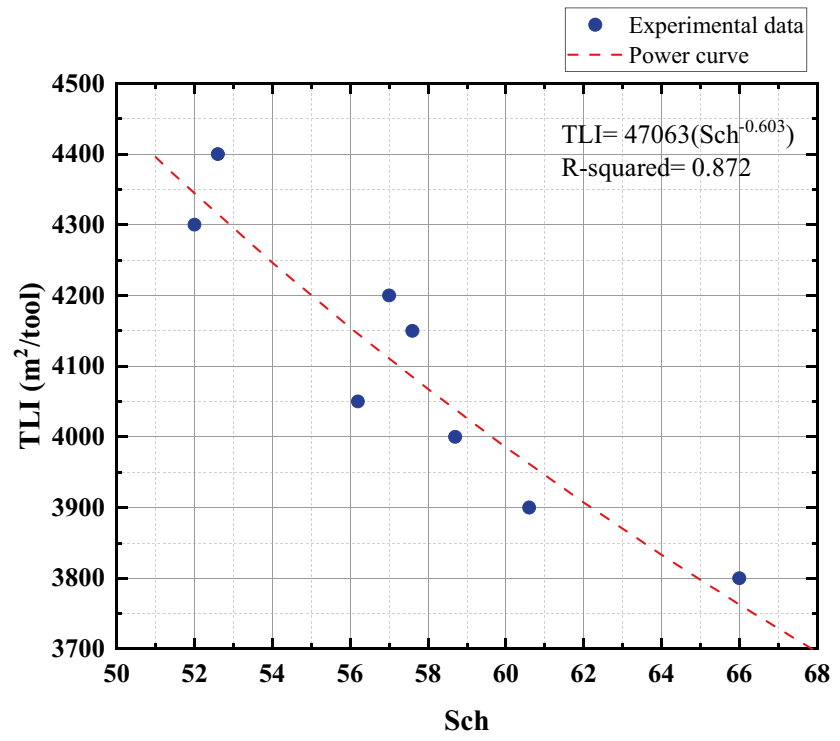

(a)

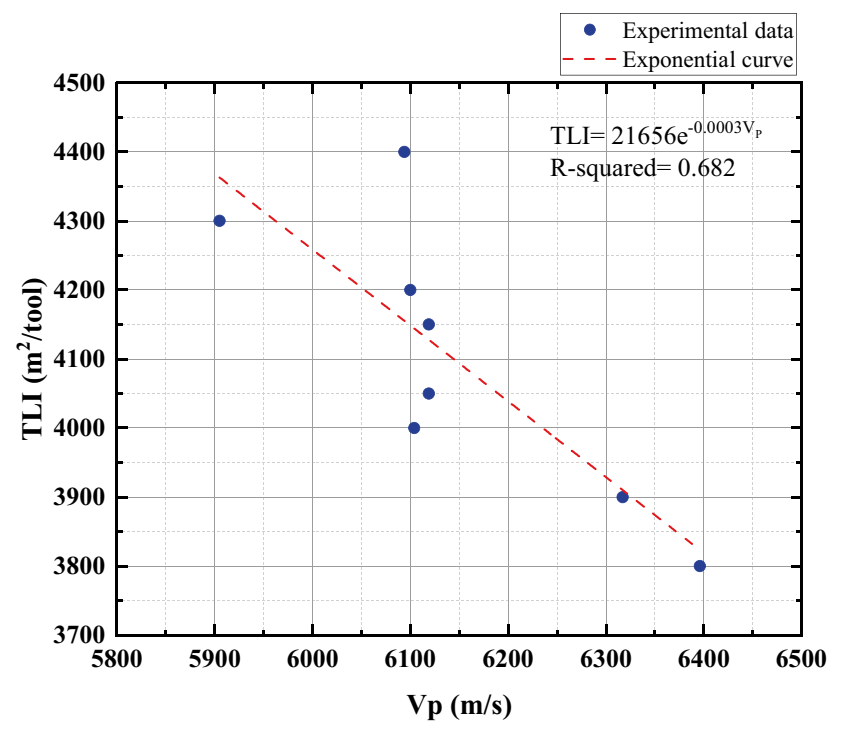

(c)

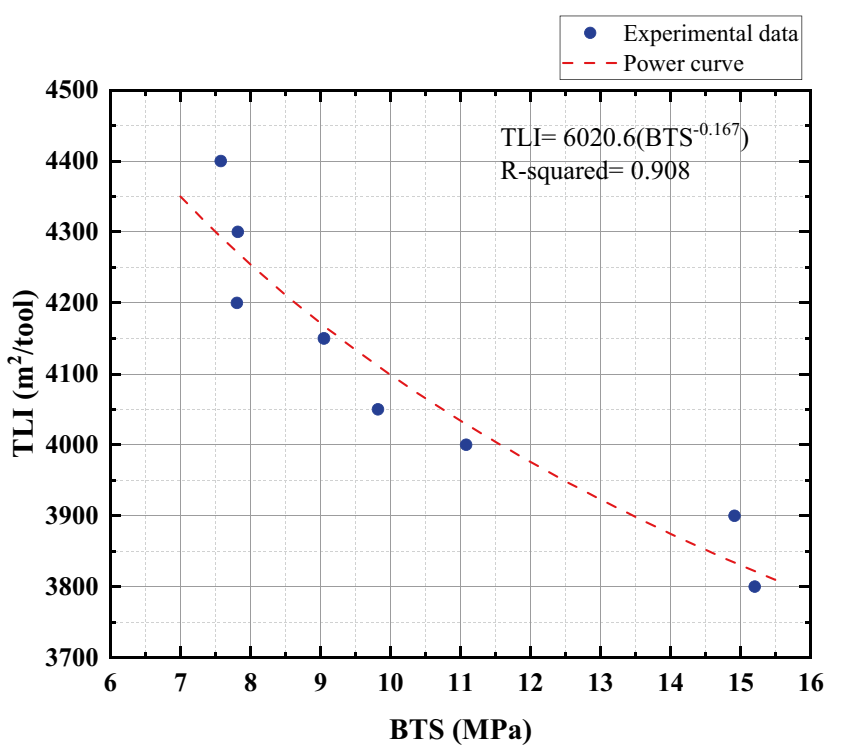

(b)

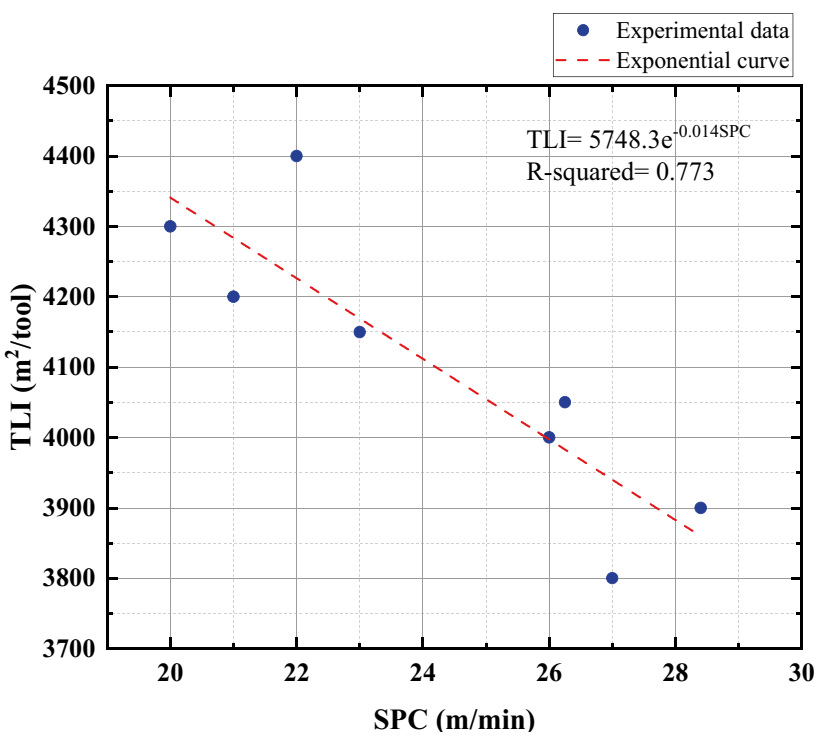

(d)

Fig. 3 (a) Relationship between Sch and TLI. (b) Relationship between BTS and TLI. (c) Relationship between V $V_{P}$ and TLI. (d) Relationship between SPC and TLI

Having applied the stepwise command, the Brazilian tensile strength was then determined as the main parameter that affects the cutting tool life index. A linear model is therefore developed for the prediction of the tool life index with a coefficient of determination of 0.863 , and is expressed in the form of Eq. 2 below. Figure 5 shows the relationship between the actual TLI values and those predicted by Eq. 2 .

$T L I=(-60.451 \times B T S)+4729.219$

\section{Multiple non-linear regression analysis}

The non-linear multivariate regression models are similar to the linear multivariate regression models. Their difference is concerned with considering a non-linear equation (commonly in a logarithmic form) for the regulation of the relationship between the input and output parameters (McCormick and Salcedo 2017). The logarithmic model expressed is in the form of Eq. 3. In this equation, $Y$ is the dependent variable, $X_{i}(I=1$ to $n)$ are independent variables, and $a$ and $b_{i}$ are constant regression coefficients. 

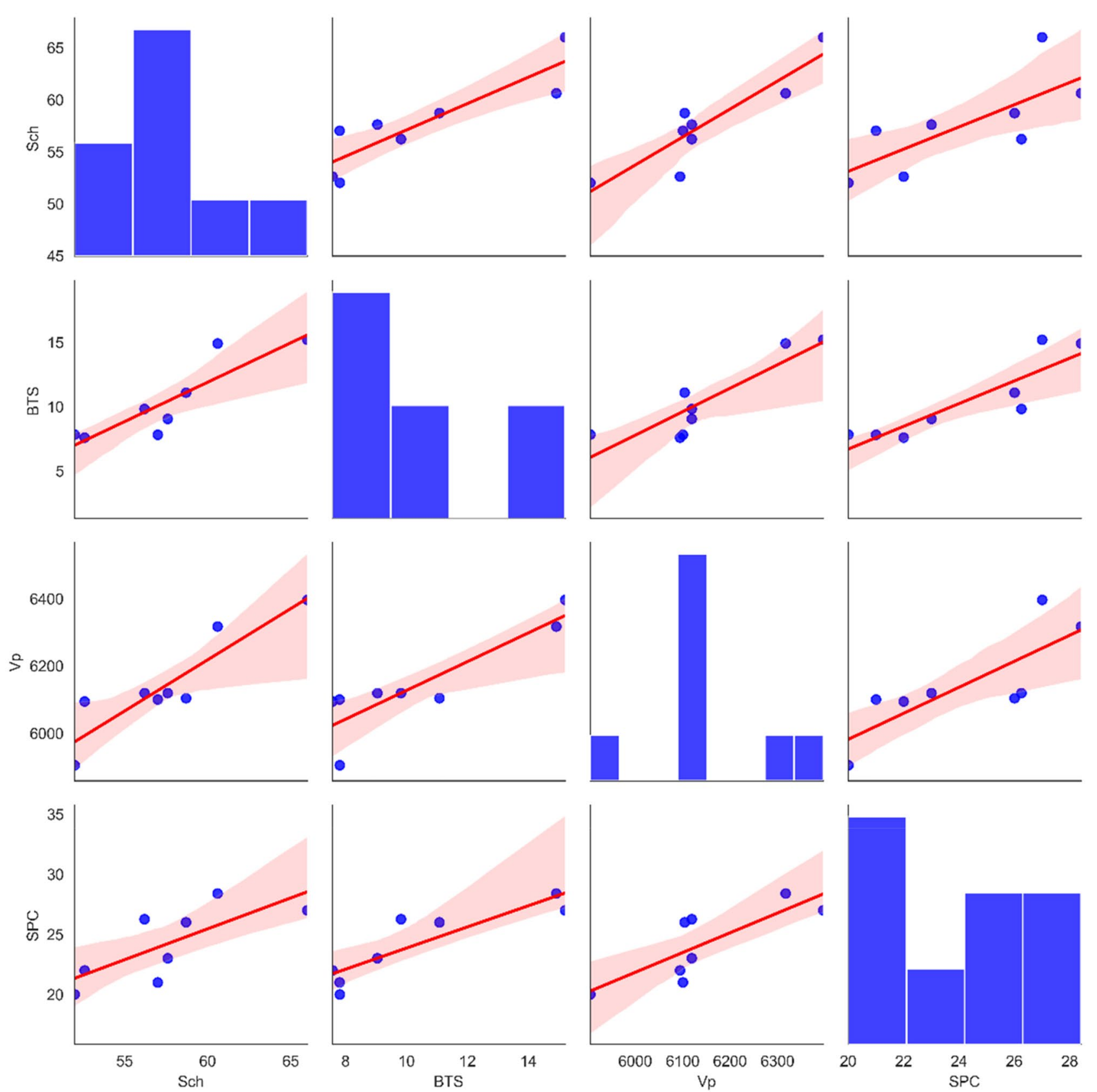

Fig. 4 Pair of the Schmidt hammer hardness, Brazilian tensile strength, $P$-wave velocity, and the cutting speed of cutting discs

Table 8 Pearson correlation between input parameters

\begin{tabular}{lllll}
\hline $\begin{array}{l}\text { Pearson } \\
\text { correlation }\end{array}$ & Sch & BTS & $\boldsymbol{V}_{\boldsymbol{p}}$ & SPC \\
\hline Sch & 1 & - & - & - \\
BTS & 0.883 & 1 & - & - \\
$\mathrm{V}_{\mathrm{p}}$ & 0.904 & 0.884 & 1 & - \\
SPC & 0.741 & 0.883 & 0.797 & 1 \\
\hline
\end{tabular}

Finally, in the SPSS software environment, the predictive model for the tool life index is converted into the form of Eq. 4 with a coefficient of determination of 0.983 .

$$
\begin{aligned}
& Y=a X_{1}^{b_{1}} \times X_{2}^{b_{2}} \times X_{3}^{b_{3}} \times \ldots \times X_{n}^{b_{n}} \\
& T L I=16.277 \times S c h^{-0.493} \times B T S^{-0.071} \times V_{P}^{0.924} \times S P C^{-0.115}
\end{aligned}
$$




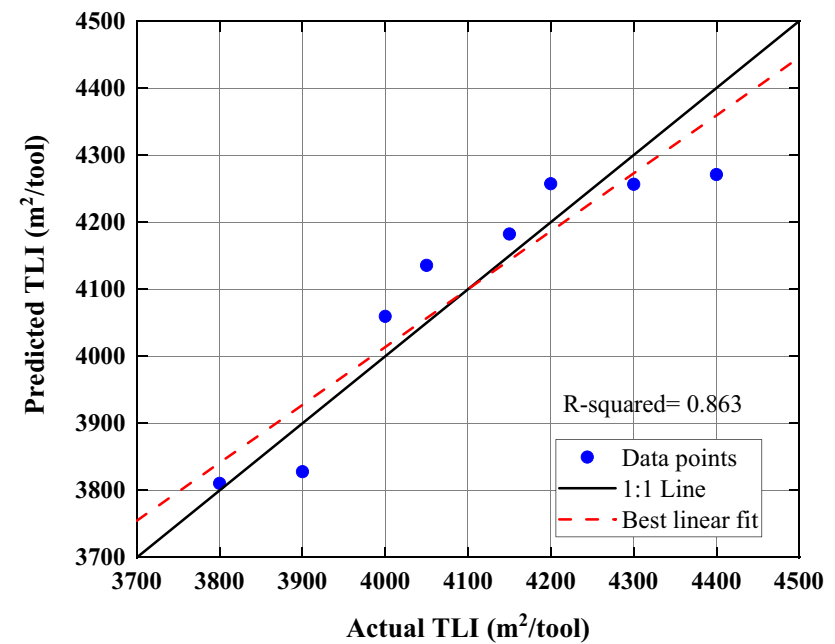

Fig. 5 The relationship between the actual and predicted TLI values (Eq. 2)

According to Eq. 4, there is an indirect relationship between the TLI parameter and the parameters of BTS, Sch, and SPC. However, there is an assumed direct relationship (assumption 1) between the parameters TLI and $V_{p}$. This assumption is not followed in engineering logic. Similar to the reasoning in the previous section ("Multiple linear regression analysis"), it is due to the multi-collinearity problem between the input parameters (arising from the high correlation between the parameters, see Table 6). To solve this problem in SPSS software, the stepwise command can be used for the development of the regression equation.

Having applied the stepwise command, the parameter of the Brazilian tensile strength was then determined as the main parameter that affects the cutting tool life index. A non-linear model is therefore developed for the prediction of the tool life index with a coefficient of determination of 0.905 , and is expressed as the form of Eq. 5 . Figure 6 depicts the relationship between the actual TLI values and those predicted by Eq. 5 .

$T L I=6020.545 \times B T S^{-0.167}$

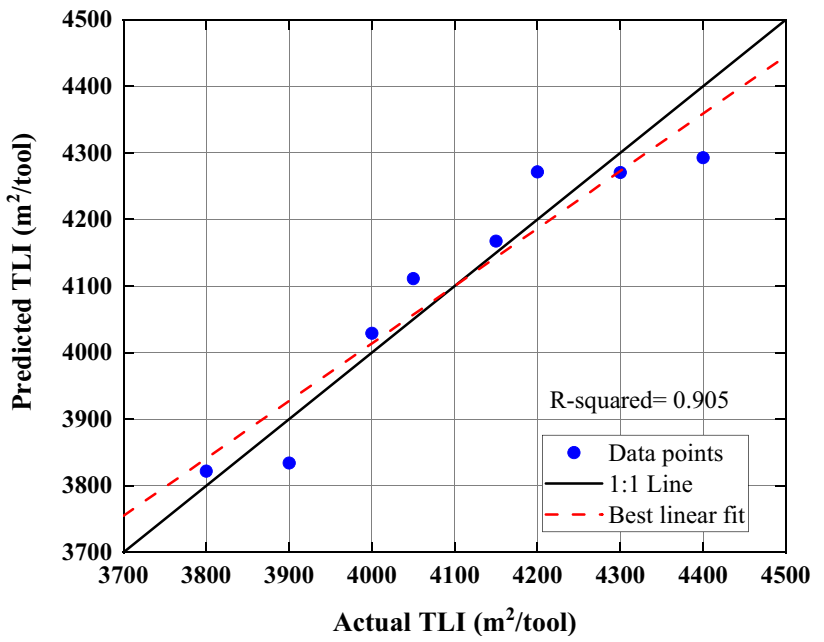

Fig. 6 The relationship between the actual and predicted TLI values (Eq. 5)

\section{Performance of the developed models}

In this section, the performance of the developed models are evaluated based on three statistical indicators: the coefficient of determination $\left(R^{2}\right)$, the variance accounted for (VAF), and the root mean square error (RMSE). The values of VAF and RMSE are computed following Eqs. 6 and 7, respectively (Minaeian and Ahangari 2013). In these equations, $A_{i}$ is the actual value of the cutting tool life index, $P_{i}$ is the predictive value of the cutting tool life index, and $N$ is the number of data items.

$\operatorname{VAF}=\left[1-\frac{\operatorname{var}\left(A_{i}-P_{i}\right)}{\operatorname{var}\left(A_{i}\right)}\right] \times 100$

$R M S E=\sqrt{\frac{1}{n} \sum_{i=1}^{n}\left(A_{i}-P_{i}\right)^{2}}$

If the performance coefficient of the VAF is 100 and the performance coefficient of the RSME is zero, then the predicted equations have a high performance (Jahed Armaghani et al. 2015). Table 9 represents the values of $\mathrm{R}^{2}$, VAF, and RMSE for the developed models (linear and non-linear equations).
Table 9 Values of performance coefficients of the models developed

\begin{tabular}{llll}
\hline Performance coefficient & $\begin{array}{l}\text { Coefficient of } \\
\text { determination }\left(\boldsymbol{R}^{2}\right)\end{array}$ & $\begin{array}{l}\text { Variance accounted } \\
\text { for (VAF) }\end{array}$ & $\begin{array}{l}\text { Root mean } \\
\text { square error } \\
\text { (RMSE) }\end{array}$ \\
\hline Linear model (Eq. 2) & 0.863 & 86.32 & 0.698 \\
Non-linear model (Eq. 5) & 0.905 & 90.47 & 0.583 \\
\hline
\end{tabular}




\section{Summary and conclusions}

In this study, field and laboratory tests were performed to find a relationship between the physico-mechanical properties of marble stones and operational parameters of cutting process with the life index of the diamond cutting tool, which is the most crucial parameter in the building stone processing operations. In this regard, several studies were performed on eight marble stones from eight different building stone processing plants. The field surveys include investigating and evaluating the speed of cutting disc and diamond cutting tool life, and the laboratory tests include determining the physico-mechanical properties of marble stones such as Schmidt hammer hardness, density, porosity, Brazilian tensile strength, uniaxial compressive strength, and $P$-wave velocity. The results of the simple regression analysis revealed that the parameters of Schmidt hammer hardness, Brazilian tensile strength, $P$-wave velocity, and the speed of the cutting disc were the most effective parameters on the TLI. Afterwards, SPSS software was employed to develop the linear and non-linear multivariate statistical models to develop predictive TLI models based on these four variables. The developed models were against the engineering logic due to the multi-collinearity problem. To solve this issue, the stepwise method was applied in SPSS software, and consequently, the Brazilian tensile strength was determined as the main parameter that affects the cutting tool life index. Having developed the linear and non-linear equations based on the Brazilian tensile strength, two models were developed and evaluated using three criteria: the coefficient of determination, the variance accounted for, and the rootmean-square error. For the linear model, the coefficient of determination is 0.863 , the variance accounted for is 86.32 , and the root-mean-square error is 0.698 . For the non-linear model, the coefficient of determination is 0.905 , the variance accounted for is 90.470 , and the root-mean-square error is 0.583 .

The results of the performance evaluation revealed that the non-linear model developed herein yields high performance. Therefore, this non-linear model can compute the diamond cutting tool life with acceptable accuracy in the marble cutting process. Consequently, the prediction of this model can be used to prevent the occurrence of possible undesirable scenarios, such as breaking the cutting discs and crushing stones during the cutting operation. Since, the processing plants can simply estimate the lifespan of their cutting tools by considering the mechanical properties of their stone, the manufacturing throughput increases and leads to the enhancement of profitability.

Finally, it is noteworthy that there are some limitations in this study, which can be considered as a starting point for future complementary research. In this sense, the main considerations to be made are the following: (1) The developed models are only valid for marble stones and should be applied only for stones with the same physico-mechanical properties employed to develop the models. This shortcoming is due to the limited number of studied stones, and the suggested models can become more comprehensive and general by considering other types of stones and accumulating more data. (2) Although the mineralogical composition has a remarkable role on the cutting tool life, it has not been considered in this study because the range of mineralogical variations for the studied marbles is narrow. It is clear that considering other types of stones with various mineralogical compositions in the future can lead to more comprehensive models that include mineralogical properties as important participating parameters.

Supplementary information The online version contains supplementary material available at https://doi.org/10.1007/s10064-021-02381-5.

Funding Open Access funding provided thanks to the CRUE-CSIC agreement with Springer Nature.

\section{Declarations}

Conflict of interest The authors declare no competing interests.

Open Access This article is licensed under a Creative Commons Attribution 4.0 International License, which permits use, sharing, adaptation, distribution and reproduction in any medium or format, as long as you give appropriate credit to the original author(s) and the source, provide a link to the Creative Commons licence, and indicate if changes were made. The images or other third party material in this article are included in the article's Creative Commons licence, unless indicated otherwise in a credit line to the material. If material is not included in the article's Creative Commons licence and your intended use is not permitted by statutory regulation or exceeds the permitted use, you will need to obtain permission directly from the copyright holder. To view a copy of this licence, visit http://creativecommons.org/licenses/by/4.0/.

\section{References}

Akhyani M, Sereshki F, Mikaeil R (2018) An investigation of the effect of toughness and brittleness indexes on ampere consumption and wear rate of a circular diamond saw. Rud Geol Naft Zb 33. https:// doi.org/10.17794/rgn.2018.4.8

Al-Subaihi AA (2002) Variable selection in multivariable regression using SAS/IML. J Stat Softw 7(12):1-20. https://doi.org/10. 18637/jss.v007.i12

Aydin G, Karakurt I, Aydiner K (2013) Wear performance of saw blades in processing of granitic rocks and development of models for wear estimation. Rock Mech Rock Eng 46(6):1559-1575. https://doi.org/10.1007/s00603-013-0382-y

Bulut B, Baydogan M, Kayali ES (2021) Effect of aluminium and silver addition on the wear characteristics of circular diamond saw blades for cutting ankara andesite rocks. Wear 474:203867. https://doi.org/10.1016/j.wear.2021.203867 
Bayram F, Kulaksiz S (2021) Evaluation of rock cutting performance of diamond segmented frame saw in terms of diamond segment wear. Int J Rock Mech Min Sci 139:104657. https://doi.org/10. 1016/j.ijrmms.2021.104657

Buyuksagis IS (2007) Effect of cutting mode on the sawability of granites using segmented circular diamond sawblade. J Mater Process Technol 183(2-3):399-406. https://doi.org/10.1016/j.jmatprotec. 2006.10.034

Buyuksagis IS, Rostami J, Yagiz S (2020) Development of models for estimating specific energy and specific wear rate of circular diamond saw blades based on properties of carbonate rocks. Int J Rock Mech Min Sci 135:104497. https://doi.org/10.1016/j.ijrmms. 2020.104497

Cassapi VB (1987) Application of rock hardness and abrasive indexing to rock excavating equipment selection. University of Nottingham, England

Dormishi A, Ataei M, Kakaie R (2019) Performance evaluation of gang saw using hybrid ANFIS-DE and hybrid ANFIS-PSO algorithms. J Min Environ 10(2):543-557. http://jme.shahroodut.ac.ir/article_ 1152.html

Dormishi A, Ataei M, Mikaeil R, Khalokakaei R (2018) Relations between texture coefficient and energy consumption of gang saws in carbonate rock cutting process. Civ Eng J 4(2):413-421. https:// doi.org/10.28991/cej-0309101

Ersoy A, Atici U (2004) Performance characteristics of circular diamond saws in cutting different types of rocks. Diam Relat Mater 13(1):22-37. https://doi.org/10.1016/j.diamond.2003.08.016

Ertingshausen W (1985) Wear processes in sauring hard stone. Ind Diam Rev 45(510):254-258

Eyuboglu AS, Ozcelik Y, Kulaksiz S, Engin IC (2003) Statistical and microscopic investigation of disc segment wear related to sawing Ankara andesites. Int J Rock Mech Min Sci 40(3):405-414. https://doi.org/10.1016/S1365-1609(03)00002-9

Farrar DE, Glauber RR (1964) Multicollinearity in regression analysis: the problem revisited. Rev Econ Stat 49:92-107. https://doi.org/ $10.2307 / 1937887$

Fener M, Kahraman S, Ozder MO (2007) Performance prediction of circular diamond saws from mechanical rock properties in cutting carbonate rocks. Rock Mech Rock Eng 40(5):505-517. https://doi. org/10.1007/s00603-006-0110-y

Feng XT (2017) Rock mechanics and engineering volume 2: Laboratory and field testing. CRC Press, Florida

George D, Mallery P (2016) IBM SPSS Statistics 23 Step by Step. Routledge, England. https://doi.org/10.4324/9781315545899

Goktan RM, Gunes Y1lmaz N (2017) Diamond tool specific wear rate assessment in granite machining by means of knoop micro-hardness and process parameters. Rock Mech Rock Eng 50(9):2327-2343. https://doi.org/10.1007/s00603-017-1240-0

Gunes Y1lmaz N, Goktan RM, Kibici Y (2011) An investigation of the petrographic and physico-mechanical properties of true granites influencing diamond tool wear performance and development of a new wear index. Wear 271(5-6):960-969. https://doi.org/10. 1016/j.wear.2011.04.007

Güney A (2011) Performance prediction of large-diameter circular saws based on surface hardness tests for Mugla (Turkey) marbles. Rock Mech Rock Eng 44(3):357-366. https://doi.org/10. 1007/s00603-010-0119-0

Guo B, Zhang L, Cao L, Zhang T, Jiang F, Yan L (2018) The correction of temperature-dependent Vickers hardness of cemented carbide base on the developed high-temperature hardness tester. J Mater Process Technol 255:426-433. https://doi.org/10.1016/j. jmatprotec.2017.12.041

Inal S, Erkan I, Aydiner K (2019) Determination of the wear performance of diamond saw blades using inductively coupled plasma. Sadhana 44(5):1-11. https://doi.org/10.1007/s12046-019-1080-6
Jahed Armaghani D, Hajihassani M, Monjezi M, Mohamad ET, Marto A, Moghaddam MR (2015) Application of two intelligent systems in predicting environmental impacts of quarry blasting. Arab J Geosci 8(11):9647-9665. https://doi.org/10.1007/ s12517-015-1908-2

Jennings M, Wright D (1989) Guidelines for sawing stone. Ind Diam Rev 49(2):70-75

Kahraman S, Altun H, Tezekici BS, Fener M (2006) Sawability prediction of carbonate rocks from shear strength parameters using artificial neural networks. Int J Rock Mech Min Sci 43(1):157-164. https://doi.org/10.1016/j.ijrmms.2005.04.007

Liao YS, Luo SY (1992) Wear characteristics of sintered diamond composite during circular sawing. Wear 157(2):325-337. https://doi. org/10.1016/0043-1648(92)90070-O

Luo SY (1996) Characteristics of diamond sawblade wear in sawing. Int J Mach Tools Manuf 36(6):661-672. https://doi.org/10.1016/ 0890-6955(95)00071-2

Mamalis A, Schulze R, Tonshoff H (1979) The slotting of blocks of hard rock with a diamond segmented circular sawblade. Ind Diam Rev 10:356-365

McCormick K, Salcedo J (2017) SPSS statistics for data analysis and visualization. John Wiley and Sons, New Jersey

Mikaeil R, Haghshenas SS, Haghshenas SS, Ataei M (2018) Performance prediction of circular saw machine using imperialist competitive algorithm and fuzzy clustering technique. Neural Comput Appl 29(6):283-292. https://doi.org/10.1007/s00521-016-2557-4

Minaeian B, Ahangari K (2013) Estimation of uniaxial compressive strength based on P-wave and Schmidt hammer rebound using statistical method. Arab J Geosci 6(6):1925-1931. https://doi.org/ 10.1007/s12517-011-0460-y

Montgomery DC, Peck EA, Vining GG (2012) Introduction to linear regression analysis. John Wiley and Sons, New Jersey. http://pubs. sciepub.com/ajams/8/2/1/index.html

Ozcelik Y, Yilmazkaya E (2010) Performance analysis of a diamond bead in its lifetime by using single bead test machine. Global Stone Congress. https://www.researchgate.net/publication/266875209

Rajpurohit SS, Sinha RK, Sen P (2020) Influence of Cerchar hardness index of hard rock granite on wear of diamond tools. Mater Today Proc 33:5471-5475. https://doi.org/10.1016/j.matpr.2020.03.273

Sadegheslam G, Mikaeil R, Rooki R, Ghadernejad S, Ataei M (2013) Predicting the production rate of diamond wire saws using multiple nonlinear regression analysis. Geosystem Eng 16(4):275-285. https://doi.org/10.1080/12269328.2013.856276

Sánchez Delgado N, Rodríguez-Rey A, Suárez del Río LM, Díez Sarriá I, Calleja L, Ruiz de Argandoña VG (2005) The influence of rock microhardness on the sawability of Pink Porrino granite (Spain). Int J Rock Mech Min Sci 42(1):161-166. https://doi.org/10.1016/j. ijrmms.2004.08.010

Shaffiee Haghshenas S, Shirani Faradonbeh R, Mikaeil R, Haghshenas SS, Taheri A, Saghatforoush A, Dormishi A (2019) A new conventional criterion for the performance evaluation of gang saw machines. Measurement 146:159-170. https://doi.org/10.1016/j. measurement.2019.06.031

Shahdad SA, McCabe JF, Bull S, Rusby S, Wassell RW (2007) Hardness measured with traditional Vickers and Martens hardness methods. Dent Mater 23(9):1079-1085. https://doi.org/10.1016/j. dental.2006.10.001

Shrestha N (2020) Detecting Multicollinearity in Regression Analysis. Am J Appl Math Stat 8(2):39-42. https://doi.org/10.12691/ ajams-8-2-1

Strzałkowski P, Kaźmierczak U, Wolny M (2020) Assessment of the method for abrasion resistance determination of sandstones on Böhme abrasion test apparatus. Bull Eng Geol Environ 79(9):4947-4956. https://doi.org/10.1007/s10064-020-01868-x

Sun Q, Zhang J, Wang Z, Zhang H, Fang J (2016) Segment wear characteristics of diamond frame saw when cutting different granite 
types. Diam Relat Mater 68:143-151. https://doi.org/10.1016/j. diamond.2016.06.018

Traverso M, Rizzo G, Finkbeiner M (2010) Environmental performance of building materials: life cycle assessment of a typical Sicilian marble. Int J Life Cycle Assess 15(1):104-114. https:// doi.org/10.1007/s11367-009-0135-Z

Tumac D (2015) Predicting the performance of large diameter circular saws based on Schmidt hammer and other properties for some Turkish carbonate rocks. Int J Rock Mech Min Sci 75:159-168. https://doi.org/10.1016/j.ijrmms.2015.01.015

Turchetta S, Sorrentino L (2019) Forces and wear in high-speed machining of granite by circular sawing. Diam Relat Mater 100:107579. https://doi.org/10.1016/j.diamond.2019.107579

Unver B (1996) A statistical method for practical assessment of sawability of rocks. ISRM International Symposium, EUROCK 1996:59-65

Wang C, Wei X, Tang Z, Pan Z (1995) The role of coolant in granite sawing. Ind Diam Rev 55(567):156-160

Wang S, Zhang J, Dong P (2020) Comparison of wear characteristics of diamond segments under different sawing modes in sawing hard stone. Int J Refract Met Hard Mater 87:105149. https://doi.org/ 10.1016/j.ijrmhm.2019.105149
Wright DN, Wapler H, Tönshoff HK (1986) Investigations and prediction of diamond wear when sawing. CIRP Ann 35(1):239-244. https://doi.org/10.1016/S0007-8506(07)61879-4

Yavuz H, Ugur I, Demirdag S (2008) Abrasion resistance of carbonate rocks used in dimension stone industry and correlations between abrasion and rock properties. Int J Rock Mech Min Sci 45(2):260 267. https://doi.org/10.1016/j.ijrmms.2007.04.003

Yurdakul M (2015) Effect of cutting parameters on consumed power in industrial granite cutting processes performed with the multi-disc block cutter. Int J Rock Mech Min Sci 76:104-111. https://doi.org/ 10.1016/j.ijrmms.2015.03.008

Zhang H, Zhang J, Chen M, An Q (2019) The effect of operational parameters on diamond tools of frame sawing system: Wear characteristics and optimization in stone processing. Int J Refract Metal Hard Mater 84:105019. https://doi.org/10.1016/j.ijrmhm. 2019.105019

Zhang P, Wang J, Jiang L, Zhou T, Yan X, Yuan L, Chen W (2020) Influence analysis and stepwise regression of coal mechanical parameters on uniaxial compressive strength based on orthogonal testing method. Energies 13(14):3640. https://doi.org/10.3390/ en13143640 